\title{
The quality of life after transnasal microsurgical and endoscopic resection of nonfunctioning pituitary adenoma
}

\author{
Maciej Bryl ${ }^{1, A-D}$, Jowita Woźniak ${ }^{2, B-D}$, Krzysztof Dudek ${ }^{3, C}$, Bogdan Czapiga a,A, ${ }^{4, E, F}$, Paweł Tabakow 2,A,C-F \\ ${ }^{1}$ Department of Neurosurgery and Neurooncology, Medical University of Lodz, Barlicki University Hospital, Poland \\ 2 Department of Neurosurgery, Wroclaw Medical University, Poland \\ ${ }^{3}$ Faculty of Natural Sciences and Technology, Karkonosze College, Jelenia Góra, Poland \\ ${ }^{4}$ Department of Nervous System Diseases, Faculty of Health Sciences, Wroclaw Medical University, Poland \\ A - research concept and design; B - collection and/or assembly of data; C - data analysis and interpretation; \\ $D$ - writing the article; $E$ - critical revision of the article; $F$ - final approval of the article
}

\section{Address for correspondence \\ Maciej Bryl}

E-mail: bryl.maciej@gmail.com

\section{Funding sources}

None declared

Conflict of interest

None declared

Received on March 9, 2020

Reviewed on March 31, 2020

Accepted on June 2, 2020

Published online on August 3, 2020

\section{Cite as}

Bryl M, Woźniak J, Dudek K, Czapiga B, Tabakow P. The quality of life after transnasal microsurgical and endoscopic resection of nonfunctioning pituitary adenoma. Adv Clin Exp Med. 2020;29(8):921-928.

doi:10.17219/acem/123351

DOI

10.17219/acem/123351

\section{Copyright}

Copyright by Author(s)

This is an article distributed under the terms of the

Creative Commons Attribution 3.0 Unported (CC BY 3.0)

(https://creativecommons.org/licenses/by/3.0/)

\begin{abstract}
Background. A pituitary tumor can be reached by a transsphenoidal approach with the use of a microscope or an endoscope. The impact of the surgical technique on the patient's quality of life $(\mathrm{OOL})$ is of great interest to us. Currently, the development of both surgical techniques, especially the endoscopic one, is very rapid. Treatment outcomes are extremely important, especially in terms of patients' Q0L after pituitary tumor resection, irrespective of the technical aspects.
\end{abstract}

Objectives. To compare the quality of life between patients who had undergone either transsphenoidal microscopic (MTS) or endoscopic (ETS) non-functioning pituitary adenoma resection.

Material and methods. The study population consisted of 32 consecutive patients (21 for the endoscopic and 11 for the microscopic method) who had undergone pituitary adenoma resection. Their Q0L was evaluated using the World Health Organization's Quality of Life assessment tool (WHOQOL-BREF), the Sino-Nasal Outcome Test (SNOT-22) and the Visual Functioning Questionnaire (VFQ-25). Questionnaires were collected before and after surgery during the patients' hospital stay and 3 months after the surgery.

Results. The patients in the 2 groups did not differ significantly in terms of age, sex, tumor size, length of hospital stay, or QOL before the surgery. Vision-related QOL (VR-QOL) significantly improved in patients undergoing endoscopic surgery $(p<0.001)$. There were no statistically significant differences in Q0 L between the study groups at any stage of the trial $(p>0.05)$. Significantly more patients had improved Q0L after endoscopic surgery according to the WHOQOL-BREF $(p=0.005)$ and the VFQ-25 $(p=0.002)$.

Conclusions. The novel observation in this study is the significant improvement of VR-QOL in patients after endoscopic non-functioning pituitary adenoma resection in comparison to patients having microscopic resection. The microscopic method does not exacerbate rhinological symptoms more than the endoscopic one. Endoscopic surgery seems to be more beneficial for patients with pituitary adenoma, which deteriorates VR-Q0L.

Key words: pituitary adenoma, health-related quality of life, neuroendoscopy, transsphenoidal approach, microsurgery 


\section{Introduction}

In 1907, the transsphenoidal approach to pituitary lesions was adopted by Schoffler. Harvey Cushing performed his first transsphenoidal operation on a patient with acromegaly using a modified form of Schoffler's method. ${ }^{1}$ The first direct endonasal approach was described by Griffith and Veerapen in $1987 .{ }^{2}$ It is thought that the microscopic transsphenoidal approach is highly invasive and that the deeper the operating field is, the less invasive the surgery will be, due to a better angle of attack. There are 2 techniques for introducing the microscope into the anterior wall of the sphenoid sinus: 1) microscopic sublabial, with a wide angle of attack thanks to the nasal septum not being in the way; and 2) microscopic endonasal, which involves fitting a speculum under the mucosa of the nasal septum and is therefore considered to have a narrow angle of attack. In contrast, the endoscopic technique allows for the minimally invasive transsphenoidal approach, but the deeper the operating field, the higher the invasiveness due to the uncomfortable angle of attack. Again, 2 techniques can be performed - endoscopic endonasal binostril or uninostril - both with slightly different angles of attack, though the binostril technique is favored due to the contralateral location of the pivot point. Furthermore, the microscope or endoscope can be introduced submucosally or extramucosally, which is of great importance in regard to the patient's postoperative complaints. The development of both surgical techniques, especially the endoscopic one, has been rapid. Long-term treatment outcomes are important, especially in terms of the quality of life (QOL) of patients after pituitary tumor resection, irrespective of the technical aspects.

One of the most common symptoms of pituitary adenoma is visual field defect, occurring in $9-32 \%$ of patients. ${ }^{3}$ It is crucial for such a patient (and for the surgeon as well) to improve the vision-related quality of life (VR-QOL). Nowadays, it is standard procedure to perform transsphenoidal pituitary tumor resection in more than 95\% of such cases (when the tumor mass can be reached from the bottom through the sphenoethmoidal recess). ${ }^{3}$ Such a procedure (with instruments within the nasal cavity) can cause a deterioration in QOL related to ear, nose and throat complaints. Furthermore, we believe that there are many other QOL aspects which are affected during or after the surgical treatment of pituitary masses.

\section{Objectives}

Little has been written about the comprehensive assessment of overall QOL with a view to analyzing rhinologyspecific quality of life (RS-QOL) and VR-QOL in patients undergoing transsphenoidal microscopic and endoscopic non-functioning pituitary adenoma (NFPA) resection. The objective of this study was to fill the gap in the research and to juxtapose the results with the results of other authors.

\section{Material and methods}

The study initially involved 35 consecutive patients, but 3 of them were excluded due to the different surgical technique applied (a transcranial pterional approach). Ultimately, the study included 32 patients, aged 22-82 years (mean: 58 years; standard deviation $(\mathrm{SD})=14.7$ ), among them 17 men (53\%) and 15 women (47\%). Informed consent was obtained from all individual participants of the study. All patients were operated on for an NFPA between July 2012 and February 2014 at the Department of Neurosurgery in Wroclaw Medical University Hospital, Poland. They were allocated into 2 groups: the endoscopic group (group E) and the microscopic group (group M), depending on the surgical method used. Both surgical techniques were applied by 2 experienced surgeons of similar experience; one of them specialized only in the microscopic surgery of pituitary lesions, while the other one only in endoscopic procedures. Both the researchers and the participants knew which treatment method would be used. An intention-to-treat (ITT) analysis was performed and dropouts were considered in the analysis. The navigation system manufactured by Medtronic (Minneapolis, USA) was used in both techniques. Patients from group $M$ underwent a submucosal paraseptal sphenoidotomy approach to the sella turcica, while patients from group E received a submucosal binostril anterior sphenoidotomy approach. The endoscopic transsphenoidal surgery (ETS) was performed in 21 patients (12 men and 9 women; mean age: 61 years; mean tumor diameter: $2.46 \times 2.66 \times 2.44 \mathrm{~cm}$ ), while the microscopic transsphenoidal surgery (MTS) was used in 11 patients ( 5 men and 6 women; mean age: 59 years; mean tumor diameter: $2.66 \times 2.45 \times 2.70 \mathrm{~cm}$ ).

Health-related QOL (HR-QOL) was assessed using 3 questionnaires: 1) the Polish version of the World Health Organization's Quality of Life assessment tool (WHOQOLBREF) to evaluate overall $\mathrm{QOL}^{4,5} ; 2$ ) the Sino-Nasal Outcome Test 22 (SNOT-22) to assess RS-QOL ${ }^{6}$; and 3) the Visual Functioning Questionnaire 25 (VFQ-25) to evaluate VR-QOL. ${ }^{7}$ The WHOQOL-BREF is comprised of 26 items measuring the following broad domains: physical health, psychological health, social relationships, and the environmental aspect (every domain is scored from $0 \%$ to $100 \%$ and higher results indicate better QOL). The SNOT-22 contains 22 questions on chronic rhinosinusitis-related symptoms, where the symptom severity is graded from 0 to 5 , with 0 indicating no problem at all and 5 indicating the worst possible situation (a scale ranging from 0 to 110 points); high scores indicate a greater severity of rhinology-specific symptoms. The VFQ-25 consists of 25 vision-targeted questions representing 11 vision-related constructs and an additional single-item general health rating question. The VFQ-25 generates the following vision-targeted sections: general health and vision ( $0-21$ points), difficulty with activities ( $0-83$ points) and response to vision problems (0-45 points). Lower results indicate less severe vision 
problems. The questionnaires were administered 3 times to each patient: before the surgery, after the surgery (during their hospital stay, between the $3^{\text {rd }}$ and $6^{\text {th }}$ day after surgery) and 3 months after discharge. In case of any condition that could interfere with a result of a single questionnaire (e.g., upper respiratory tract infections may increase the SNOT-22 score), distribution of the questionnaire was postponed until the symptoms were resolved. Both groups of patients were compared in terms of age, sex, hospital stay after surgery, tumor size, and QOL. Better QOL was defined as a better result of the questionnaire collected after the surgery.

The normality of the distribution of variables was verified by means of the Shapiro-Wilk test. A p-value $<0.05$ was considered statistically significant. Variables with normal distribution are presented in the tables as means and standard deviation (SD). The variables whose distribution was significantly different from the normal distribution are presented as medians and interquartile ranges (IQR). Categorical variables emerge as numbers and fractions (percentage). When comparing the ratings for 3 consecutive periods, a non-parametric Friedman test was used for dependent variables. To compare quantitative variables in the 2 groups, the Mann-Whitney U test and Student's $\mathrm{t}$-test were used. The interdependence of the qualitative variables was verified using Pearson's $X^{2}$ test or Fisher's exact test. The statistics program package for STATISTICA v. 10 (StatSoft, Inc., Tulsa, USA) was used in calculations and graph creation.

\section{Results}

The age, sex and tumor size of the study groups are presented in Table 1. Both groups of patients were homogeneous in terms of age, sex and tumor diameter ( $p>0.05)$.

Tables 2 and 3 present the statistical analysis of the WHOQOL-BREF, SNOT-22 and VFQ-25 results as medians and IQR. In group $M$, there was no statistically significant improvement in QOL according to the WHOQOLBREF, SNOT-22 and VFQ-25. In group E, we observed statistically significant improvement in QOL as assessed

Table 1. Age, sex and tumor size of study groups

\begin{tabular}{|c|c|c|c|c|}
\hline \multirow[b]{2}{*}{ Variable } & \multirow{2}{*}{$\begin{array}{c}\text { Total } \\
n=32\end{array}$} & \multicolumn{2}{|c|}{ Group } & \multirow{2}{*}{$\begin{array}{c}\text { Evs M } \\
p \text {-value }\end{array}$} \\
\hline & & $\begin{array}{l}\text { endoscopic } \\
\qquad n=21\end{array}$ & $\begin{array}{c}\text { microscopic } \\
n=11\end{array}$ & \\
\hline $\begin{array}{l}\text { Age [years] } \\
\text { median (IQR) } \\
\text { range }\end{array}$ & $\begin{array}{c}60.5(13.5) \\
22-82\end{array}$ & $\begin{array}{l}61(14) \\
22-82\end{array}$ & $\begin{array}{l}59(19) \\
22-74\end{array}$ & $0.463^{a}$ \\
\hline $\begin{array}{l}\text { Sex } \\
\text { male } \\
\text { female }\end{array}$ & $\begin{array}{l}17(53.1 \%) \\
15(46.9 \%)\end{array}$ & $\begin{array}{c}12(57.1 \%) \\
9(42.9 \%)\end{array}$ & $\begin{array}{l}5(45.4 \%) \\
6(54.6 \%)\end{array}$ & $\begin{array}{l}0.398^{b} \\
0.412^{b}\end{array}$ \\
\hline $\begin{array}{l}\text { Tumor diameter }[\mathrm{cm}] \\
\text { transverse } \\
\text { cranio-caudal } \\
\text { antero-posterior }\end{array}$ & $\begin{array}{l}2.53 \pm 0.96 \\
2.59 \pm 1.12 \\
2.53 \pm 0.87\end{array}$ & $\begin{array}{l}2.46 \pm 0.90 \\
2.66 \pm 1.14 \\
2.44 \pm 0.78\end{array}$ & $\begin{array}{l}2.66 \pm 1.09 \\
2.45 \pm 1.13 \\
2.70 \pm 1.05\end{array}$ & $\begin{array}{l}0.571^{c} \\
0.612^{c} \\
0.429^{c}\end{array}$ \\
\hline
\end{tabular}

a Mann-Whitney U test; ${ }^{b}$ Fisher's exact test; c Student's t-test; IQR - interquartile range.

Table 2. Statistical analysis of the median results of WHOQOL-BREF, SNOT-22 and VFQ-25 for group E

\begin{tabular}{|c|c|c|c|c|}
\hline Questionnaire & Preoperative & Postoperative & After 3 months & $\begin{array}{l}\text { ANOVA }^{a} \\
p \text {-value }\end{array}$ \\
\hline \multicolumn{5}{|c|}{ WHOQOL-BREF (broad domain) } \\
\hline Physical, median (range) & $63.19(44-88)$ & $50.19(19-69)$ & $63.70(38-75)$ & 0.267 \\
\hline Psychological, median (range) & $63.13(44-88)$ & $69.9(19-94)$ & $69.60(25-81)$ & 0.350 \\
\hline Social, median (range) & $75.25(44-100)$ & $75.25(25-100)$ & $75.25(25-100)$ & 0.703 \\
\hline Environment, median (range) & $69.25(25-88)$ & $75.18(25-94)$ & $75.25(25-88)$ & 0.397 \\
\hline \multicolumn{5}{|c|}{ SNOT-22 (broad domain) } \\
\hline Median (range) & $35.28(8-64)$ & $42.17(1-65)$ & $22.21(3-64)$ & 0.097 \\
\hline \multicolumn{5}{|c|}{ VFQ-25 (broad domain) } \\
\hline General, median (range) & $11.40(7-17)$ & $10.40(6-17)$ & $8.30(7-19)$ & 0.010 \\
\hline Everyday, median (range) & $30.20(13-52)$ & $22.18(13-45)$ & $16.13(13-43)$ & $<0.001$ \\
\hline Response, median (range) & $22.18(9-42)$ & $18.20(9-46)$ & $11.14(9-44)$ & 0.023 \\
\hline
\end{tabular}

a Friedman ANOVA; ANOVA - analysis of variance; WHOQOL-BREF - World Health Organization's Quality of Life assessment tool; SNOT-22 - Sino-Nasal Outcome Test; VFQ-25 - Visual Functioning Questionnaire. 


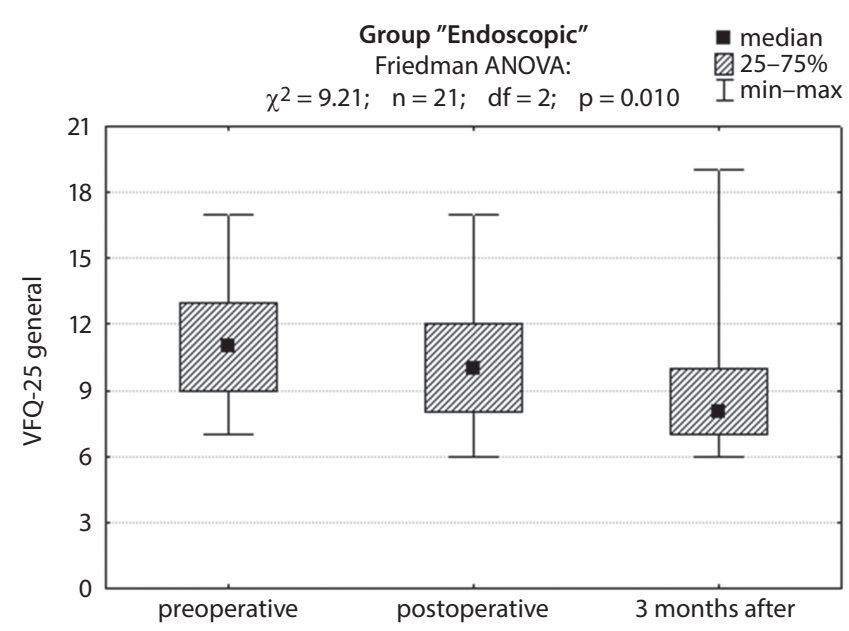

Fig. 1. Comparison of the VR-QOL self-assessment in VFQ-25 (GENERAL HEALTH AND VISION) and results of Friedman ANOVA test throughout the study (endoscopic group)

using the VFQ-25 (Fig. 1). Moreover, some improvement was observed as indicated by the WHOQOL-BREF and the SNOT-22, although the differences were not statistically significant ( $\mathrm{p}>0.05)$.

Tables 4-6 compare quality of life in both groups before and after surgery and 3 months after discharge. There were no statistically significant differences between the groups in those 3 time points ( $p>0.05$ ).

The mean length of hospital stay for group E was 6.5 days, and for group M 8.5 days. The difference in duration of hospital stay was not statistically significant (Fig. 2).

An improvement in QOL was frequently observed among patients who underwent ETS (Table 7). It was statistically significant $(\mathrm{p}<0.05)$ in all domains of the WHOQOLBREF and in difficulty with activities and response to vision problems from the VFQ-25.

Better outcomes in the physical domain from the WHOQOL-BREF were observed in 12 patients (57\%) who

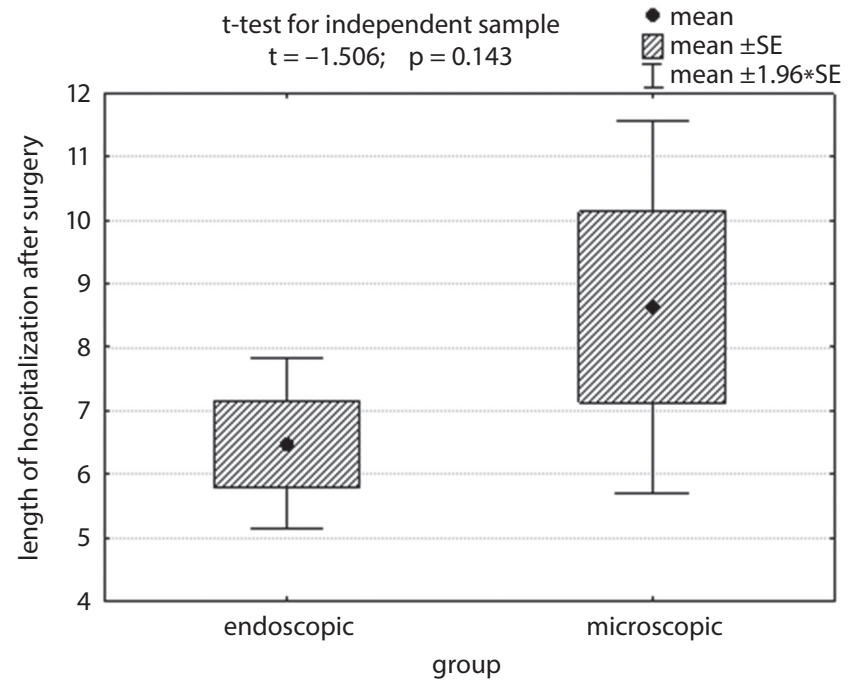

Fig. 2. Comparison of the length of hospitalization after surgery and results of t-test

had received ETS as compared with 2 patients (18\%) who had received MTS ( $\mathrm{p}=0.039)$; in the psychological domain, improvements were noted in 11 patients (52\%) after ETS compared to 1 patient $(9 \%)$ after MTS ( $\mathrm{p}=0.018)$; in the social and environmental domains, the results were statistically significant. Better outcomes, as assessed using SNOT-22, were observed in 12 patients (57\%) after ETS in comparison with 5 patients (45\%) after MTS, although the outcomes were not statistically significant $(\mathrm{p}=0.398)$. According to the VFQ-25, better outcomes in difficulty with everyday activities were observed in 16 patients (76\%) after ETS compared with 2 patients $(18 \%)$ after MTS ( $p=0.003)$. With regard to response to vision problems, better results were obtained in 14 patients (67\%) after ETS compared to 1 patient (9\%) after MTS $(\mathrm{p}=0.002)$.

Furthermore, comparing the difference between the mean results of questionnaires before and 3 months after

Table 3. Statistical analysis of the median results of WHOQOL-BREF, SNOT-22 and VFQ-25 for group M

\begin{tabular}{|c|c|c|c|c|}
\hline Questionnaire & Preoperative & Postoperative & After 3 months & $\begin{array}{l}\text { ANOVA }^{a} \\
p \text {-value }\end{array}$ \\
\hline \multicolumn{5}{|c|}{ WHOQOL-BREF (broad domain) } \\
\hline Physical, median (range) & $63.19(38-69)$ & $56.25(38-81)$ & $56.28(13-81)$ & 0.862 \\
\hline Psychological, median (range) & $63.25(31-81)$ & $69.13(31-81)$ & $63.22(19-81)$ & 0.368 \\
\hline Social, median (range) & $75.31(31-100)$ & $69.25(31-100)$ & $78.25(31-81)$ & 0.232 \\
\hline Environment, median (range) & $63.38(44-94)$ & $63.12(50-81)$ & $72.38(31-94)$ & 0.554 \\
\hline \multicolumn{5}{|c|}{ SNOT-22 (broad domain) } \\
\hline Median (range) & $20.28(0-61)$ & $32.38(0-73)$ & $17.23(0-70)$ & 0.150 \\
\hline \multicolumn{5}{|c|}{ VFQ-25 (broad domain) } \\
\hline General, median (range) & $13.60(4-17)$ & $10.60(4-16)$ & $8.80(4-16)$ & 0.119 \\
\hline Everyday, median (range) & $33.19(13-48)$ & $29.20(13-44)$ & $21.23(13-48)$ & 0.168 \\
\hline Response, median (range) & $13.21(9-41)$ & $17.22(9-39)$ & $10.18(9-36)$ & 0.751 \\
\hline
\end{tabular}

a Friedman ANOVA; ANOVA - analysis of variance; WHOQOL-BREF - World Health Organization's Quality of Life assessment tool; SNOT-22 - Sino-Nasal Outcome Test; VFQ-25 - Visual Functioning Questionnaire. 
Table 4. Comparison of mean values and SD of the quality of life questionnaire results in both groups before surgery

\begin{tabular}{|l|c|c|c|}
\hline \multirow{2}{*}{ Questionnaire } & $\begin{array}{c}\text { Endoscopic } \\
\text { group } \\
\text { WHOQOL-BREF (broad domain) }\end{array}$ & $\begin{array}{c}\text { Microscopic } \\
\text { group }\end{array}$ & $\begin{array}{c}\text { Mann-Whitney } \\
\text { U test } \\
\text { p-value }\end{array}$ \\
\hline Physical & $\begin{array}{c}54.8 \pm 14.5 \\
\text { Psychological }\end{array}$ & $58.9 \pm 12.9$ & 0.242 \\
\hline Social & $71.4 \pm 16.6$ & $72.6 \pm 22.7$ & 0.927 \\
\hline Environment & $63.5 \pm 17.7$ & $73.8 \pm 17.6$ & 0.751 \\
\hline & SNOT-22 (broad domain) & \\
\hline Median & $33.4 \pm 15.8$ & $25.6 \pm 21.0$ & 0.197 \\
\hline General & $11.6 \pm 3.1$ & $10.6 \pm 4.2$ & 0.706 \\
\hline Everyday & $30.4 \pm 11.4$ & $28.5 \pm 12.8$ & 0.968 \\
\hline Response & $22.9 \pm 11.8$ & $14.1 \pm 9.3$ & 0.234 \\
\hline
\end{tabular}

SD - standard deviation; WHOQOL-BREF - World Health Organization's Quality of Life assessment tool; SNOT-22 - Sino-Nasal Outcome Test; VFQ-25 - Visual Functioning Questionnaire.

Table 5. Comparison of mean values and SD of the quality of life questionnaire results in both groups after surgery

\begin{tabular}{|c|c|c|c|}
\hline Questionnaire & $\begin{array}{l}\text { Endoscopic } \\
\text { group }\end{array}$ & $\begin{array}{c}\text { Microscopic } \\
\text { group }\end{array}$ & $\begin{array}{c}\text { Mann-Whitney } \\
\text { U test } \\
\text { p-value }\end{array}$ \\
\hline \multicolumn{4}{|c|}{ WHOQOL-BREF (broad domain) } \\
\hline Physical & $51.4 \pm 15.2$ & $56.4 \pm 12.0$ & 0.620 \\
\hline Psychological & $63.9 \pm 17.6$ & $61.8 \pm 16.9$ & 0.766 \\
\hline Social & $73.2 \pm 19.9$ & $71.0 \pm 24.4$ & 0.796 \\
\hline Environment & $69.0 \pm 16.4$ & $69.0 \pm 11.1$ & 0.372 \\
\hline \multicolumn{4}{|c|}{ SNOT-22 (broad domain) } \\
\hline Median & $35.3 \pm 14.2$ & $37.0 \pm 21.3$ & 0.706 \\
\hline \multicolumn{4}{|c|}{ VFQ-25 (broad domain) } \\
\hline General & $10.3 \pm 3.0$ & $9.1 \pm 3.8$ & 1.000 \\
\hline Everyday & $25.7 \pm 10.5$ & $25.0 \pm 9.2$ & 0.552 \\
\hline Response & $21.1 \pm 12.5$ & $15.5 \pm 8.6$ & 0.796 \\
\hline
\end{tabular}

SD - standard deviation; WHOQOL-BREF - World Health Organization's Quality of Life assessment tool; SNOT-22 - Sino-Nasal Outcome Test; VFQ-25 - Visual Functioning Questionnaire.

discharge, the p-values confirmed the benefit of ETS over MTS in obtaining greater improvement in patient VR-QOL, but no significant difference in RS-QOL (Table 8).

\section{Discussion}

It must be noted that the literature lacks research which juxtaposes 2 surgical methods of NFPA treatment in the context of comprehensively assessing the patients' QOL. According to the WHO, QOL is defined as an individual's perception of their position in life in the context of the culture and value systems in which they live
Table 6. Comparison of mean values and SD of the quality of life questionnaire results in both groups 3 months after discharge

\begin{tabular}{|l|c|c|c|}
\hline Questionnaire & $\begin{array}{c}\text { Endoscopic } \\
\text { group } \\
\text { WHOQOL-BREF (broad domain) }\end{array}$ & $\begin{array}{c}\text { Microscopic } \\
\text { group }\end{array}$ & $\begin{array}{c}\text { Mann-Whitney } \\
\text { U test } \\
\text { p-value }\end{array}$ \\
\hline Physical & $58.8 \pm 9.2$ & $54.8 \pm 21.9$ & 0.770 \\
\hline Psychological & $63.2 \pm 14.2$ & $58.6 \pm 19.7$ & 0.626 \\
\hline Social & $75.0 \pm 18.7$ & $67.9 \pm 19.5$ & 0.608 \\
\hline Environment & $68.8 \pm 16.4$ & $69.8 \pm 23.1$ & 0.770 \\
\hline Median & SNOT-22 (broad domain) & \\
\hline General & $26.3 \pm 16.9$ & $20.6 \pm 22.6$ & 0.272 \\
\hline Everyday & VFQ-25 (broad domain) & \\
\hline Response & $9.7 \pm 3.6$ & $9.5 \pm 4.6$ & 0.575 \\
\hline
\end{tabular}

SD - standard deviation; WHOQOL-BREF - World Health Organization's Quality of Life assessment tool; SNOT-22 - Sino-Nasal Outcome Test; VFQ-25 - Visual Functioning Questionnaire.

Table 7. Comparison of the number of patients whose quality of life outcome was higher

\begin{tabular}{|c|c|c|c|c|}
\hline \multirow[b]{2}{*}{ Questionnaire } & \multirow{2}{*}{$\begin{array}{l}\text { Total } \\
n=32\end{array}$} & \multicolumn{2}{|c|}{ Group } & \multirow{2}{*}{$\begin{array}{c}\text { E vs M } \\
p \text {-value }\end{array}$} \\
\hline & & $\begin{array}{l}\text { endoscopic } \\
\qquad n=21\end{array}$ & $\begin{array}{c}\text { microscopic } \\
n=11\end{array}$ & \\
\hline \multicolumn{5}{|c|}{ WHOQOL-BREF (broad domain) } \\
\hline Physical & $14(43.8 \%)$ & $12(57.1 \%)$ & $2(18.2 \%)$ & $0.039^{a}$ \\
\hline Psychological & $12(37.5 \%)$ & 11 (52.4\%) & $1(9.1 \%)$ & $0.018^{\mathrm{a}}$ \\
\hline Social & $10(31.2 \%)$ & $10(47.6 \%)$ & $0(0.0 \%)$ & $0.005^{\mathrm{a}}$ \\
\hline Environment & $11(34.4 \%)$ & $10(47.6 \%)$ & $1(9.1 \%)$ & $0.033^{\mathrm{a}}$ \\
\hline \multicolumn{5}{|c|}{ SNOT-22 (broad domain) } \\
\hline Median & $17(53.1 \%)$ & $12(57.1 \%)$ & $5(45.4 \%)$ & $0.398^{a}$ \\
\hline \multicolumn{5}{|c|}{ VFQ-25 (broad domain) } \\
\hline General & $16(50.0 \%)$ & $12(57.1 \%)$ & $4(36.4 \%)$ & $0.229^{a}$ \\
\hline Everyday & $18(56.2 \%)$ & $16(76.2 \%)$ & $2(18.2 \%)$ & $0.003^{a}$ \\
\hline Response & $15(46.9 \%)$ & $14(66.7 \%)$ & $1(9.1 \%)$ & $0.002^{\mathrm{a}}$ \\
\hline
\end{tabular}

a Fisher's test; WHOQOL-BREF - World Health Organization's Quality of Life assessment tool; SNOT-22 - Sino-Nasal Outcome Test; VFQ-25 - Visual Functioning Questionnaire.

and in relation to their goals, expectations, standards, and concerns. ${ }^{4}$ The authors analyzed patients' QOL regarding both ETS and MTS before and after the surgery (during the hospital stay) and 3 months after discharge. The choice of a three-month postoperative period was due to a study by Little et al., which showed that RS-QOL after ETS improves 3 months after a procedure; also, Okamoto et al. used a three-month period in their VR-QOL assessment. ${ }^{3,8}$

Similar research methods to those used in our study have been reported by other authors. Dekkers et al. examined the QOL in patients with NFPA in remission during long-term follow-up after MTS using 4 tests: the Hospital 
Table 8. Comparison of differences between the mean results before and 3 months after surgery in both groups

\begin{tabular}{|l|c|c|c|c|}
\multirow{2}{*}{ Questionnaire } & \multicolumn{2}{|c|}{ Endoscopic group } & \multicolumn{2}{c|}{ Microscopic group } \\
\cline { 2 - 5 } & mean \pm SD & p-value & mean \pm SD & p-value \\
\hline \multirow{4}{*}{ Physical } & $4.0 \pm 13.0$ & 0.168 & $-4.1 \pm 15.4$ & 0.474 \\
\hline Psychological & $-1.5 \pm 12.7$ & 0.601 & $-3.9 \pm 6.4$ & 0.132 \\
\hline Social & $3.7 \pm 23.8$ & 0.488 & $-4.8 \pm 7.4$ & 0.113 \\
\hline Environment & $5.3 \pm 18.9$ & 0.214 & $-4.0 \pm 11.0$ & 0.338 \\
\hline & SNOT-22 (broad domain) & \\
\hline Median & $-7.1 \pm 15.8$ & 0.051 & $-5.0 \pm 14.6$ & 0.365 \\
\hline General & $-1.9 \pm 3.4$ & 0.022 & $-1.1 \pm 1.7$ & 0.108 \\
\hline Everyday & $-8.8 \pm 9.3$ & $<0.001$ & $-1.4 \pm 4.8$ & 0.448 \\
\hline Response & $-4.5 \pm 6.5$ & 0.005 & $2.8 \pm 8.2$ & 0.374 \\
\hline
\end{tabular}

SD - standard deviation; WHOQOL-BREF - World Health Organization's Quality of Life assessment tool; SNOT-22 - Sino-Nasal Outcome Test; VFQ-25 - Visual Functioning Questionnaire.

Anxiety and Depression Scale (HADS), the Multidimensional Fatigue Index (MFI-20), the Nottingham Health Profile (NHP), and Short Form 36 (SF-36). Their conclusion was that QOL is considerably lower in patients after successful treatment of NFPA. ${ }^{9}$ Wolf et al. used the Headache Impact Test (HIT-6) and the SF-36 to assess QOL - preoperatively and at 6 weeks and 6 months after ETS for pituitary adenoma. The results of their study confirmed that surgery can significantly decrease headaches in patients with pituitary adenomas by 6 months postoperatively, particularly in younger patients, whose preoperative QOL is usually deteriorated. ${ }^{10}$ Tanemura et al. evaluated QOL in patients with NFPA after ETS using the SF-36, the General Health Questionnaire 30 (GHQ30) and the Numerical Rating Scale (NRS) for pain, administering them at 3 time points: immediately before surgery, and 1 month and 6 months postoperatively. The SF-36 baseline value of visual function-impaired NFPA patients was lower than that in a normal population. On the SF-36 and GHQ30, mental summary scores generally increased 1 month after the surgery and remained stable for 6 months. It was found that the strongest factor related to QOL was visual function. ${ }^{11}$ Fathalla et al. evaluated QOL in patients after ETS for acromegaly. They collected the RAND-36, the Center for Epidemiologic Studies Depression Scale (CES-D) and the Pituitary QOL validated questionnaires from 20 patients with acromegaly who had undergone ETS. Clearly, transsphenoidal surgery improves QOL in acromegaly. Additionally, the authors demonstrated the important role of the patient-physician relationship in QOL and the need to measure QOL along with the traditional measures of outcome. ${ }^{12}$ Karppinen et al. examined 137 patients after transsphenoidal surgery for NFPA and compared their QOL with that of a healthy population. They demonstrated that overall HR-QOL was near-normal after medium-term follow-up and that the most impaired domains were vision and sexual activity. Comorbidities are strong predictors of impaired HR-QOL. ${ }^{13}$ In the available literature, we found publications in which the authors examined QOL in patients with pituitary tumors compared to a healthy population - e.g., following the SF-36 questionnaire, Johnson et al. proved that patients with a pituitary adenoma had significantly lower QOL than a normal population in terms of physical and mental status. ${ }^{14}$ Goudakos et al. used a literature review and metaanalysis, including their own experience, and analyzed the efficacy and safety of ETS in comparison with MTS. There were no significant differences in regards to the remission rate of hormone hypersecretion or cerebrospinal fluid (CSF) leaks, but postoperative diabetes insipidus and other complications were less frequent in patients after ETS. ${ }^{15}$ The ETS is clearly superior to MTS, which was also confirmed in the literature reviews conducted by Rotenberg et al. ${ }^{16}$ and Schaberg et al. ${ }^{17}$

In the available literature reporting on sino-nasal disorders in patients operated on for pituitary tumors, the most commonly found assessment tool is the SNOT-22, which is widely used as a means of evaluating ear, nose and throat disorders in patients with pituitary tumors. Graham et al. used this test to assess RS-QOL in a group of 71 patients with pituitary tumors who had undergone ETS and 122 consecutive patients who had had an open procedure. For ETS, it was found that the mean hospital stay was shorter (4.1 days compared with 6 days for open procedures) and the overall complication rate was lower (33.5\% compared to $43.4 \%$ for open procedures); while cerebrospinal fluid leaks were more frequent in the endoscopy group, the mean SNOT-22 score was lower for patients in the endoscopy group. Patients in the endoscopy group had a significantly lower rhinology-specific mean score, and more patients who had presented with visual deterioration showed improvement after ETS. ${ }^{18}$ In our opinion, comparing the QOL between patients undergoing a transcranial approach with patients undergoing an endonasal approach is pointless because the indications for these procedures are vastly different; therefore, the neurosurgeon has to deal with 2 differing pituitary tumors, which are incomparable. Little et al. compared RS-QOL and health status in 218 patients undergoing MTS (111 patients) or ETS (107 patients). They used 3 tests: 1) the Anterior Skull Base Nasal Inventory-12 (ASK Nasal-12) to evaluate postoperative rhinology-specific symptoms; 2) the SF-36; and 3) the European Quality of Life Questionnaire (EQ-5D) to evaluate overall QOL. Patients from the ETS group were more likely to have postoperative nasal deterioration. Three months after the surgery, patients undergoing ETS reported statistically better RS-QOL than patients undergoing MTS. ${ }^{19}$ McCoul et al. found that the ETS to the skull base can result in an increased intranasal area without a detrimental effect on rhinology-specific symptoms. ${ }^{20}$ Hong et al. carried out a study of olfactory function and 
RS-QOL after pituitary tumor ETS and MTS. There was no significant difference in subjective olfaction in the CrossCultural Smell Identification Test (CC-SIT) or in scores on the Butanol Threshold Test (BTT) between the ETS and MTS groups. ${ }^{21}$ Olfactory disorders may persist for at least 4 months after pituitary MTS. ${ }^{22}$ In our study, the results of RS-QOL in both groups were comparable. McCoul et al. analyzed QOL in 81 patients after endoscopic endonasal resection of pituitary tumors. The patients filled out the Anterior Skull Base Questionnaire (ASBQ) and the SNOT-22 preoperatively, and then at regular intervals after the surgery. The endoscopic resection of a pituitary adenoma is associated with long-term improvement in sitespecific QOL and stability in RS-QOL when assessed preand postoperatively with validated instruments, yet partial resection correlated with worse QOL. In turn, extrasellar tumor extension, visual disturbances, intraoperative CSF leakage, and the reconstruction technique during surgery did not influence postoperative QOL. ${ }^{23}$

Okamoto et al. described the use of the National Eye Institute's VFQ-25 to evaluate VR-QOL in 74 patients with pituitary adenoma before and 3 months after MTS. The authors showed that MTS can significantly improve VR-QOL in pituitary adenoma, and that the preoperative VFQ-25 composite score and visual field defect in the better-seeing eye are particularly important predictors associated with the postoperative VR-QOL. The VFQ-25 proved to be a useful tool in the assessment of patients admitted for surgical treatment of pituitary tumors. ${ }^{3}$

In our study, ETS proved to have a greater impact on patients' QOL; in the literature, ETS has gained a clear advantage over MTS. In our opinion, the reason for better outcomes after ETS is primarily the better visibility of the operation field provided by the endoscope, which goes hand in hand with a more efficient decompression of the optic chiasm and better visual control of the pituitary gland, which is almost always visible and therefore remains undamaged. Moreover, an endoscope facilitates extended approaches to the skull base lesions (suprasellar, retrosellar and parasellar), which is beyond the abilities of the microscope. It should also be pointed out that the choice of method does not affect RS-QOL, which we did not expect when planning the research. Despite different invasive methods, this aspect of QOL was similar.

Rudmik et al. demonstrated an interesting approach to pituitary tumor surgery in studying the cost-effectiveness of endoscopic compared to pituitary MTS. It was found that ETS is a more cost-effective intervention than MTS. ${ }^{24}$ The unusual perspective of this subject was also demonstrated by Little et al., who examined the inpatient resource utilization for patients undergoing pituitary ETS or MTS. The authors demonstrated that the use of ETS for pituitary lesions does not adversely affect the utilization of resources for inpatients; however, the primary factors of hospital charges, in order of importance, were length of stay, a diagnosis of Cushing's disease and - to a lesser extent - the use of ETS. ${ }^{25}$ Yadav et al. stressed the role of the cooperation between a neurosurgeon and an otolaryngologist, cadaveric dissection, practice on models, and observation of live surgeries in pituitary ETS. The ETS, according to the authors, is a superior surgical option in most pituitary adenomas. ${ }^{26}$ Strychowsky et al. also found that ETS of pituitary adenomas seems to be safe and efficacious when compared to the traditional MTS and may offer some benefits. ${ }^{27}$ On the other hand, Iwai et al. compared a single surgeon's experience operating on pituitary tumors with the use of MTS compared to ETS. They analyzed the results of treatment in a group of 100 patients (124 procedures) treated through the sublabial transsphenoidal approach and 45 patients (54 procedures) treated with binostril ETS performed by a single surgeon. The patients who underwent ETS had less statistically significant intraoperative blood loss, experienced less pain and presented less need for postoperative hormone replacement therapy. ${ }^{28}$ Zaidi et al. investigated the impact of the surgeon's experience on the outcome after surgery. In their study, patients had been treated either by a less experienced surgeon (100 independent cases) who practices fully endoscopic surgery exclusively or by a very experienced surgeon $(1,800$ independent cases) who practices microscopic surgery exclusively. The authors concluded that a less experienced surgeon using ETS was able to achieve outcomes similar to those of an experienced surgeon using MTS in a cohort of patients with NFPAs smaller than $60 \mathrm{~cm}^{3} .^{29}$

The results of our study showed that ETS is more favorable to patients in the case of pituitary tumor surgery, which corresponds with the findings of other articles. The patients in this study who underwent ETS achieved considerably greater improvement in the overall quality of life, as assessed with the WHOQOL-BREF and in VR-QOL, as assessed with the VFQ-25. Many studies have confirmed that ETS is currently preferred to MTS of a pituitary tumor, especially in the context of VR-QOL, a view which is also validated by the results of our study. Although few studies have proven that ETS is associated with less severe outcome in RS-QOL, our study does not confirm these findings.

It should be mentioned that this study had several limitations that may have potentially affected the results and led to bias. One of them is the small sample population of the study. Additionally, objective assessment of patients' QOL is virtually obsolete, taking into account that that pituitary adenomas occur in different volumes, configurations and microscopic appearance, and that every patient has different anatomical conditions within the nasal cavity and different expectations regarding the effectiveness of treatment. In this study, both groups of patients were homogenous with regard to age, sex and adenoma size, and the conclusions are based on the differences in questionnaire results collected before and after the surgery, thereby avoiding other conditions that may affect the results of a single questionnaire. 


\section{Conclusions}

The novel observation from this study is the significant improvement in VR-QOL of patients after pituitary ETS in comparison to patients undergoing MTS. The MTS does not deteriorate RS-QOL more than ETS. Endoscopic surgery seems to be more beneficial for patients with pituitary adenoma, which can deteriorate VR-QOL.

\section{ORCID iDs}

Maciej Bryl (1) https://orcid.org/0000-0001-5300-2788

Jowita Woźniak (10 https://orcid.org/0000-0002-5536-961X

Krzysztof Dudek (1) https://orcid.org/0000-0002-9442-989X

Bogdan Czapiga (10) https://orcid.org/0000-0002-9819-2455

Paweł Tabakow (ㄷ) https://orcid.org/0000-0001-8638-3871

\section{References}

1. Cohen-Gadol AA, Liu JK, Laws ER Jr. Cushing's first case of transsphenoidal surgery: The launch of the pituitary surgery era. J Neurosurg. 2005;103(3):570-574.

2. Fatemi N, Dusick JR, de Paiva Neto MA, Kelly DF. The endonasal microscopic approach for pituitary adenomas and other parasellar tumors: A 10-year experience. Neurosurgery. 2008;63(4):244-256.

3. Okamoto Y, Okamoto F, Yamada S, Honda M, Hiraoka T, Oshika T. Vision-related quality of life after transsphenoidal surgery for pituitary adenoma. Invest Ophthalmol Vis Sci. 2010;51(7):3405-3410.

4. The WHOQOL Group: Development of the World Health Organization WHOQOL-BREF quality of life assessment. Psychol Med. 1998; 28(3):551-558

5. Wołowicka L, Jaracz K. Polska wersja WHOQOL - WHOQOL 100 i WHOQOL-BREF [In:] Jakość życia w naukach medycznych. Poznań, Poland: Wydawnictwo Akademii Medycznej w Poznaniu; 2001: 235-280.

6. Morley AD, Sharp HR. A review of sinonasal outcome scoring systems: Which is best? Clin Otolaryngol. 2006;31(2):103-109.

7. Mangione CM, Lee PP, Gutierrez PR, Spritzer K, Berry S, Hays RD; National Eye Institute Visual Function Questionnaire Field Test Investigators. Development of the 25-item National Eye Institute Visual Function Questionnaire. Arch Ophthalmol. 2001;119(7):1050-1058.

8. Little AS, Kelly D, Milligan J, et al. Predictors of sinonasal quality of life and nasal morbidity after fully endoscopic transsphenoidal surgery. J Neurosurg. 2001;122(6):1458-1465.

9. Dekkers OM, van der Klaauw AA, Pereira AM, et al. Quality of life is decreased after treatment for nonfunctioning pituitary macroadenoma. J Clin Endocrinol Metab. 2006;91(9):3364-3369.

10. Wolf A, Goncalves S, Salehi F, et al. Quantitative evaluation of headache severity before and after endoscopic transsphenoidal surgery for pituitary adenoma. J Neurosurg. 2016;124(6):1627-1633.

11. Tanemura E, Nagatani T, Aimi Y, Kishida Y, Takeuchi K, Wakabayashi T. Quality of life in nonfunctioning pituitary macroadenoma patients before and after surgical treatment. Acta Neurochir. 2012;154(10): 1895-1902.

12. Fathalla H, Cusimano MD, Alsharif OM, Jing R. Endoscopic transsphenoidal surgery for acromegaly improves quality of life. Can J Neurol Sci. 2014;41(6):735-741.
13. Karppinen A, Ritvonen E, Roine R, et al. Health-related quality of life in patients treated for non-functioning pituitary adenomas during the years 2000-2010. Clin Endocrinol (Oxf). 2016;84(4):532-539. doi:10. 1111/cen.12967

14. Johnson MD, Woodburn CJ, Vance ML. Quality of life in patients with a pituitary adenoma. Pituitary. 2003;6(2):81-87.

15. Goudakos JK, Markou KD, Georgalas C. Endoscopic versus microscopic trans-sphenoidal pituitary surgery: A systematic review and meta-analysis. Clin Otolaryngol. 2011;36(2):212-220.

16. Rotenberg B, Tam S, Ryu WHA, Duggal N. Microscopic versus endoscopic pituitary surgery: A systematic review. Laryngoscope. 2010; 120(7):1292-1297.

17. Schaberg MR, Vijay KA, Schwartz TH, Cobb W. Microscopic versus endoscopic transnasal pituitary surgery. Curr Opin Otolaryngol Head Neck Surg. 2010;18(1):8-14.

18. Graham SM, Iseli TA, Karnell LH, Clinger JD, Hitchon PW, Greenlee JDW. Endoscopic approach for pituitary surgery improves rhinologic outcomes. Ann Otol Rhinol Laryngol. 2009;118(9):630-635.

19. Little AS, Kelly DF, Milligan J, et al. Comparison of sinonasal quality of life and health status in patients undergoing microscopic and endoscopic transsphenoidal surgery for pituitary lesions: A prospective cohort study. J Neurosurg. 2015;123(3):799-807.

20. McCoul ED, Patel AS, Bedrosian JC, Anand VK, Schwartz TH. Intranasal cross-sectional area and quality of life changes following endoscopic transsphenoidal skull base surgery. Int Forum Allergy Rhinol. 2015;5(12):1124-1128. doi:10.1002/alr.21602

21. Hong SD, Nam H, Seol HJ, et al. Endoscopic binostril versus transnasal transseptal microscopic pituitary surgery: Sinonasal quality of life and olfactory function. Am J Rhinol Allergy. 2015;29(3):221-225.

22. Wang S, Chen Y, Li J, Wei L, Wang R. Olfactory function and quality of life following microscopic endonasal transsphenoidal pituitary surgery. Medicine (Baltimore). 2015;94(4):e465. doi:10.1097/MD. 0000000000000465

23. McCoul ED, Bedrosian JC, Akselrod O, Anand VK, Schwartz TH. Preservation of multidimensional quality of life after endoscopic pituitary adenoma resection. J Neurosurg. 2015;123(3):813-820.

24. Rudmik L, Starreveld YP, Vandergrift WA, Banglawala SM, Soler ZM. Cost-effectiveness of the endoscopic versus microscopic approach for pituitary adenoma resection. Laryngoscope. 2015;125(1):16-24.

25. Little AS, Chapple K, Jahnke H, White WL. Comparative inpatient resource utilization for patients undergoing endoscopic or microscopic transsphenoidal surgery for pituitary lesions. J Neurosurg. 2014;121(1):84-90.

26. Yadav Y, Sachdev S, Parihar V, Namdev H, Bhatele PR. Endoscopic endonasal trans-sphenoid surgery of pituitary adenoma. J Neurosci Rural Pract. 2012;3(3):328-337.

27. Strychowsky J, Nayan S, Reddy K, Farrokhyar F, Sommer D. Purely endoscopic transsphenoidal surgery versus traditional microsurgery for resection of pituitary adenomas: Systematic review. J Otolaryngol Head Neck Surg. 2011;40(2):175-185.

28. Iwai Y, Yoshimura M, Terada A, Yamanaka K, Koshimo N. Transsphenoidal surgery for pituitary tumors from microsurgery to the endoscopic surgery: Single surgeon's experience [in Japanese]. No Shinkei Geka. 2011;39(2):141-147.

29. Zaidi HA, Awad AW, Bohl MA, et al. Comparison of outcomes between a less experienced surgeon using a fully endoscopic technique and a very experienced surgeon using a microscopic transsphenoidal technique for pituitary adenoma. J Neurosurg. 2015;16:1-9. 